\title{
Utero-cutaneous Fistula after Multiple Abdominal Myomectomies: A Case Report
}

\author{
Mehmet Özgür Akkurt, And Yavuz, Burak Tatar, Mehmet Okan Özkaya, Elif İlknur Ekici
}

Department of Gynecology and Obstetrics, Süleyman Demirel University Faculty of Medicine, Isparta, Turkey

Background: Utero-cutaneous fistula (UCF) is an extremely rare entity and only a few case reports have been published. Most UCFs develop secondary to postpartum or postoperative complications.

Case Report: A 42 year-old woman began to complain from bleeding and malodorous discharge through her abdominal incision scar. The fistula tract with a thickness of $8 \mathrm{~mm}$ was observed between the uterus and wound using magnetic resonance imaging (MRI). The risks and benefits of conservative treatment have been discussed; the patient demanded definitive treat- ment, so hysterectomy and excision of the fistulous tract was performed. Histopathology of the fistulous tract showed endometrial epithelization of the tract lined by granulation.

Conclusion: There are many causes of such an extremely rare entity. Patients should be counseled for medical or surgical treatment considering their age, accompanied uterine pathologies such as fibroids and fertility expectations.

Keywords: Abdominal myomectomy, post-operative complication, utero-cutaneous fistula
Uterocutaneous fistula (UCF) is an extremely rare entity that is an abnormal communication between two epithelial surfaces, the uterus and the skin (1). Most UFCs develop secondary to postpartum or postoperative complications. Other possible causes of this rare occurrence are intra-uterine devices and endometriosis (2). We report here a case of UCF, which developed following myomectomy and was treated surgically.

\section{CASE PRESENTATION}

A 42-year-old woman was referred to our clinic for bleeding through her abdominal incision scar during menstruation (Figure 1). She had undergone an abdominal myomectomy for a single large anterior fibroid 12 years previously. Also, a second abdominal myomectomy operation was performed three months prior to presentation for recurrent single anterior uterine fibroid. After surgery, her first menstruation cycle was normal. The patient began to suffer from bleeding and a malodorous discharge from her incision scar two months after surgery. On abdominal examination, the uterus was anteverted, sized about eight weeks gravid with multiple intramural fibroids, and there was a low transverse scar about $10 \mathrm{~cm}$ in length that had a sinus opening of $10 \mathrm{~mm}$. The patient was a virgin and declined vaginal examination and the methylene blue test because she did not want to risk damaging the hymen. UCF was suspected with transabdominal sonography (Voluson 730; General Electric, Tiefenbach, Austria) (Figure 2) and the diagnosis was confirmed by MRI (MAGNETOM Symphony, A Tim System 1.5T eco; Siemens, Erlangen, Germany) (Figure 3 and 4). A fistulous tract with a thickness of $8 \mathrm{~mm}$ was observed between the uterus and the abdominal scar in the MRI. The patient had no wish for future childbearing and

This study was presented at the $13^{\text {th }}$ National Congress of Gynecology and Obstetrics, 11-15 May 2015, Antalya, Turkey.

Address for Correspondence: Dr. Mehmet Özgür Akkurt, Department of Gynecology and Obstetrics, Süleyman Demirel University Faculty of Medicine, Isparta, Turkey

Phone: +90 5056313115 e-mail: mozgurakkurt@gmail.com

Received: 19.12 .2014 Accepted: $16.04 .2015 \cdot$ DOI: $10.5152 /$ balkanmedj.2015.151206

Available at www.balkanmedicaljournal.org

Akkurt MÖ, Yavuz A, Tatar B, Özkaya MO, Ekici Eİ. Uterocutaneous fistula after multiple abdominal myomectomy: a case report.

Balkan Med J 2015;32:426-8 


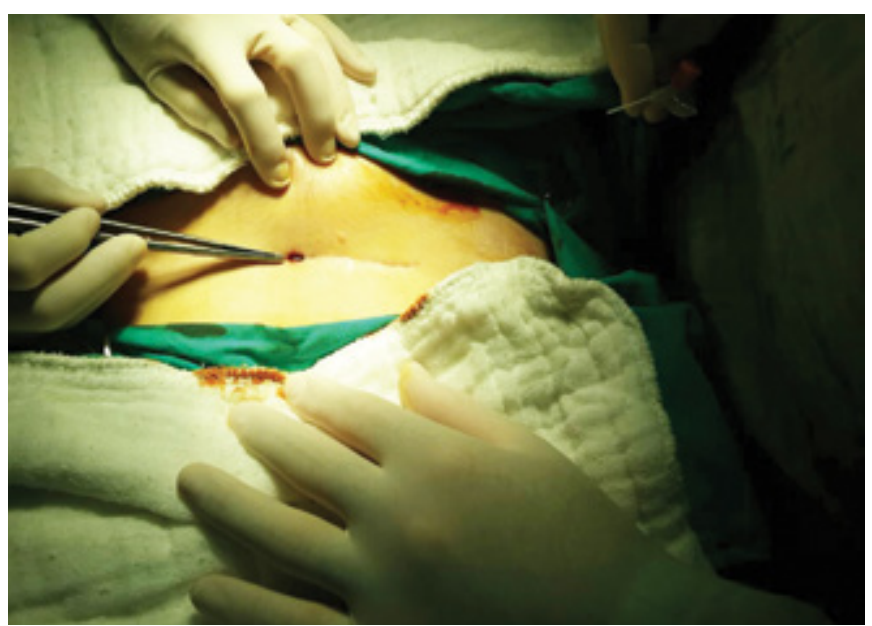

FIG. 1. The fistulous opening in the abdominal incision scar

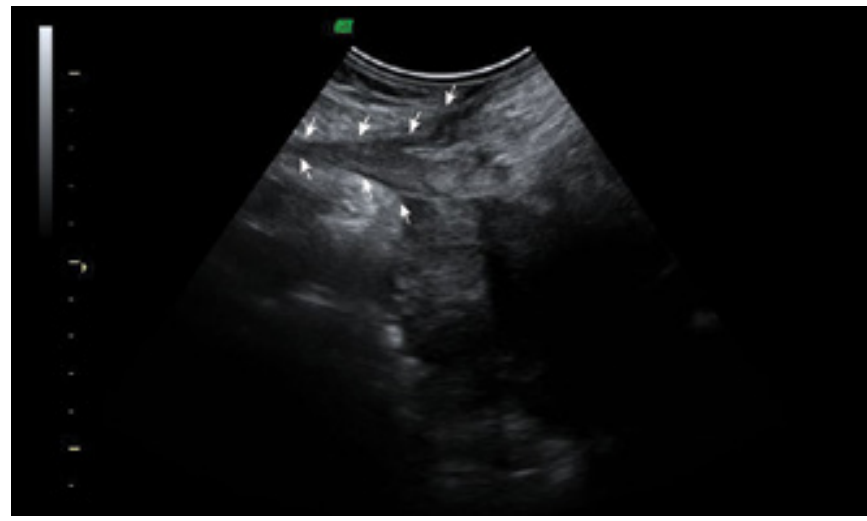

FIG. 2. Two dimensional sonography view shows fistulous tract (arrows)

underwent explorative laparotomy and hysterectomy. Intraoperatively, the fistula was seen to be extended to skin from the right cornual part of the uterus. Endometrial epithelialization of the fistula tract was observed grossly visible during the operation. Histopathology of the fistulous tract showed endometrial epithelization and the tract lined by granulation. Also, histopathological examination showed several uterine fibroids with various dimensions. She was discharged from the hospital 5 days after the surgery and made a return visit one month later. She had no complaints and there was no pathology according to her physical examination. Written informed consent was obtained from the patient before preparation of this manuscript.

\section{DISCUSSION}

Uterocutaneous fistulas are very rare fistulas. Their diagnosis and treatment may be difficult sometimes, and there is no consensus regarding whether medical treatment is effective as

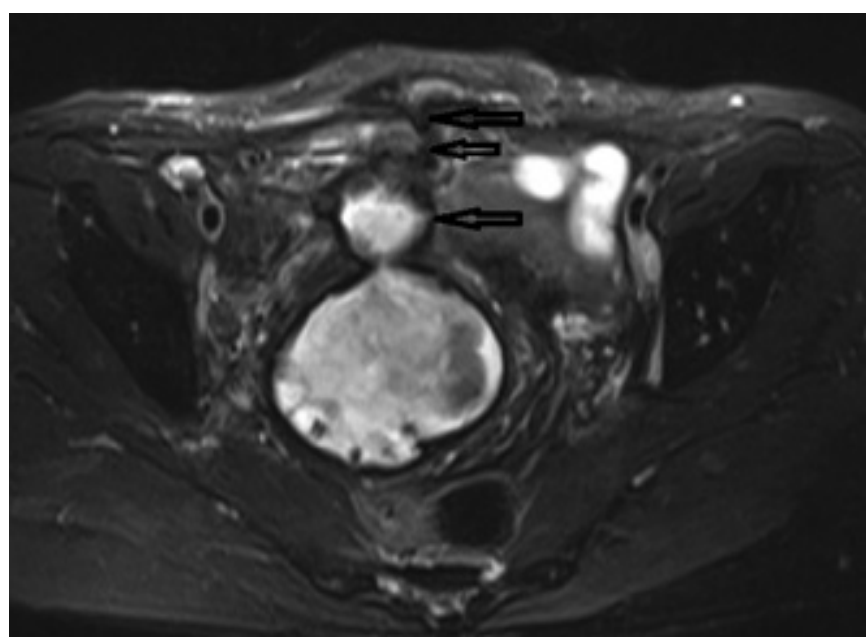

FIG. 3. Magnetic resonance imaging (MRI) shows uterocutaneous fistula (arrows)

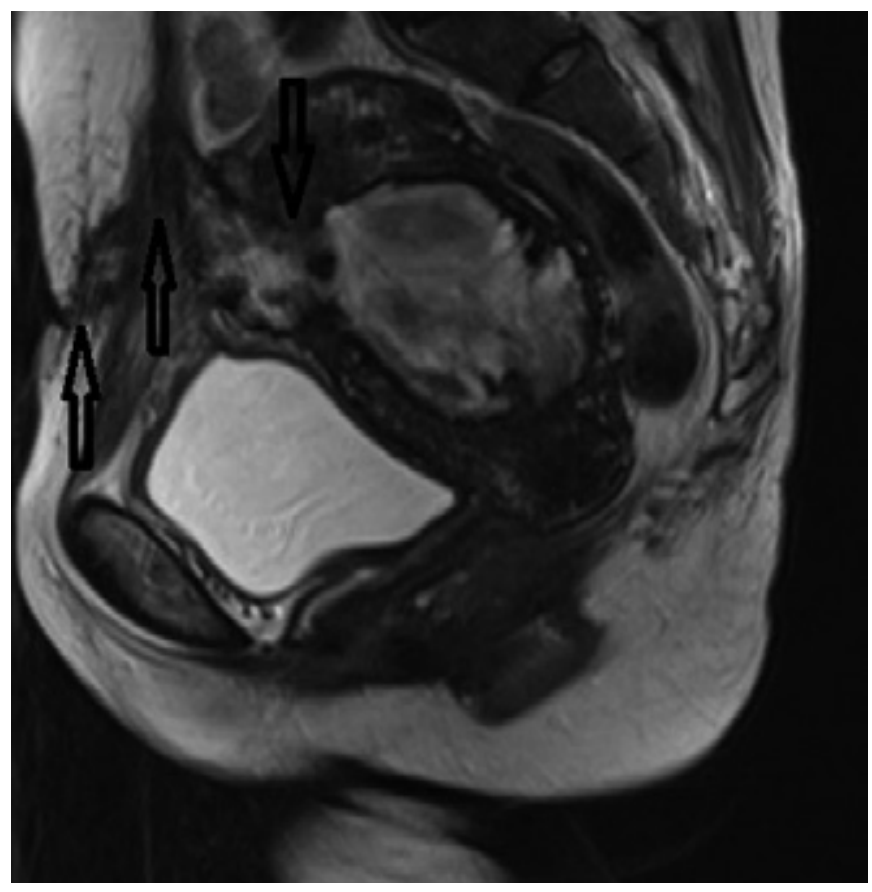

FIG. 4. Arrows show the tract and the external opening of the fistula on MRI

an initial treatment modality. Surgeons are familiar with urinary and genital fistulas but only a few cases of utero-cutaneous fistulas have been reported. The majority of patients with these fistulas have a history of a classical cesarean section. In recent years, the incidence of UCFs has decreased as a result of the decline in classical incisions for cesarean section (3). In this case, the suspected cause of this entity was a history of multiple uterine surgeries resulting in dense adhesions between the uterus and the abdominal wall, which became thinner and less vascularized. 
Blood leakage from the incision scar during menstruation is the pathognomonic finding of UCF. The diagnosis is confirmed by fistulogram, tomography, MRI or methylene blue test if there is a suspicion of this diagnosis (4). In this case, we confirmed the diagnosis by observing menstrual bleeding through the skin and the fistula tract as seen on the MRI.

Gonadotropin-releasing hormone $(\mathrm{GnRH})$ analogs may be given to aid with the spontaneous closure of the fistula tract if the patient wants her uterus to be preserved. However, only two studies have shown successful non-surgical treatment with GnRH $(5,6)$. The limitations of medical treatment are long treatment process and possible failure requiring surgical treatment. The exact treatment of UCFs is surgical excision of the fistula tract with or without hysterectomy. In these cases, women were counseled for surgery or medical treatment with a GnRH analog. For women who do not wish to preserve their fertility, hysterectomy and excision of the fistula tract should be performed.

In conclusion, many possible causes may predispose women to such an extremely rare entity and affected women need to be counseled for medical or surgical treatment considering their age, accompanying uterine pathology, and desire to preserving their fertility.

Ethics Committee Approval: Ethics committee approval was received for this study from the ethics committee of Süleyman Demirel University.

Informed Consent: Written informed consent was obtained from patients who participated in this case.

Peer-review: Externally peer-reviewed.
Author contributions: Concept - M.Ö.A., A.Y., M.Ö.O.; Design - M.Ö.A., A.Y.; Supervision - M.Ö.A., A.Y.; Resource - M.Ö.A.; Materials - E.İ.E.; Data Collection \&/or Processing - E.İ.E.; Analysis \&/ or Interpretation - M.Ö.A., A.Y.; Literature Search - M.Ö.A., A.Y.; Writing - M.Ö.A., A.Y., B.T.; Critical Reviews - M.Ö.A.

Conflict of Interest: No conflict of interest was declared by the authors.

Financial Disclosure: The authors declared that this study has received no financial support.

\section{REFERENCES}

1. Gupta SK, Shukla VK, Varma DN, Roy SK. Uterocutaneous fistula. Postgrad Med J 1993;69:822-3. [CrossRef]

2. Dragoumis K, Mikos T, Zafrakas M, Assimakopoulus E, Stamatopoulus P, Bontis J. Endometriotic uterocutaneous fistula after cesarean section. Gynecol Obstet Invest 2004;57:90-2. [CrossRef]

3. Desoouky DA, Bolan J. Uteroabdominal sinus following cesarean section. Am J Obstet Gynecol 1980;137:147-8.

4. Sönmezer M, Sahincioglu Ö, Çetinkaya E, Yazıcı F. Uterocutaneous fistula after surgical treatment of an incomplete abortion: methylene blue test to verify the diagnosis. Arch Gynecol Obstet 2009;279:225-7. [CrossRef]

5. Seyhan A, Ata B, Sidal B, Urma B. Medical treatment of uterocutaneous fistula with gonadotropin releasing hormone agonist administration. Obstet Gynecol 2008;111:526-8. [CrossRef]

6. Yadav P, Gupta S, Singh P, Tripathi S. Successful medical management of uterocutaneous fistula. Int J Gynaecol Obstet 2014;124:263-4. [CrossRef] 